the metal will be fluid enough to run from the furnace into ingot-moulds. The economy of the process consists in the saving of the labour of eight workmen making steel, and two workmen making wrought-iron; and in the superior quality of the result as compared with puddling the refined metal. The time occupied by the conversion of the refined metal into steel or wrought-iron by the process without puddling is about the same as that usually taken in puddling pig-iron.

Ordinary coke pig-iron, smelted near Pittsburgh from a mixture of hematite ore and mill cinder, has been treated by this process. The refined metal was afterwards puddled and rolled into "muck" bars, and once heated and rolled into merchant bar-iron. The pig, refined cast, and wrought-iron, have been analysed by an analytical chemist in this city. These analyses are annexed, also analyses of refined cast-iron by the English finery and German reverberatory furnace process, and of the highest standard qualities of English, French, Swedish, and Russian wrought-iron, are given for comparison, taken from Percy's "Iron Metallurgy" and Ure's Dictionary:

\begin{tabular}{|c|c|c|c|c|}
\hline \multirow{2}{*}{\multicolumn{2}{|c|}{$\begin{array}{l}\text { Pittsburgh Coke } \\
\text { Pig-iron. }\end{array}$}} & \multirow{2}{*}{\multicolumn{2}{|c|}{$\begin{array}{l}\text { Patent Refined } \\
\text { Cast-iron. }\end{array}$}} & \multirow[b]{2}{*}{ Bar-iron. } \\
\hline & & & & \\
\hline $\begin{array}{l}\text { Carbon (combined) } \\
\text { do (graphite) }\end{array}$ & $\begin{array}{l}0.2040 \\
2.7685\end{array}$ & \multicolumn{2}{|c|}{$\begin{array}{l}0.3613 \\
2.5066\end{array}$} & not deter. \\
\hline Silicon & $2 \cdot 3096$ & \multicolumn{2}{|c|}{ none } & none \\
\hline Slags (silicates) & 0.3623 & \multicolumn{2}{|c|}{0.2983} & not deter. \\
\hline \multirow{2}{*}{$\begin{array}{l}\text { Phosphorus } \\
\text { Sulphur }\end{array}$} & 0.4196 & \multicolumn{2}{|c|}{0.1029} & 0.0087 \\
\hline & 0.1298 & 0.1 & 269 & 0.0438 \\
\hline \multicolumn{5}{|c|}{ Analyses of Foreign Iron. } \\
\hline \multicolumn{2}{|c|}{$\begin{array}{l}\text { English Finery Process. } \\
\text { Refined Cast-iron. }\end{array}$} & \multicolumn{3}{|c|}{$\begin{array}{c}\text { German Reverberatory Furnace Process. } \\
\text { Pig-iron. } \\
\text { Refined Cast iron. }\end{array}$} \\
\hline Carbon & \multirow{2}{*}{$\begin{array}{l}3.07 \\
0.63\end{array}$} & \multicolumn{2}{|c|}{-} & - \\
\hline Silicon $\quad 0^{\circ}$ & & \multicolumn{2}{|l|}{$4 \cdot 66$} & 0.62 \\
\hline Phosphorus o & 0.73 & \multicolumn{2}{|l|}{0.56} & 0.50 \\
\hline Sulphux $\quad 0$ & 0.16 & \multicolumn{2}{|l|}{0.04} & 0.03 \\
\hline \multicolumn{5}{|c|}{ 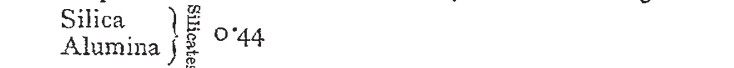 } \\
\hline $\begin{array}{l}\text { lish Wrou ght-irou. } \\
\text { ow Moor Stamp. }\end{array}$ & $\begin{array}{r}\text { Fre } \\
\text { Petin, Gau }\end{array}$ & $\begin{array}{l}\text { ench. } \\
\text { udet, \& Co. }\end{array}$ & $\begin{array}{l}\text { Swedish. } \\
\text { Hoop L. }\end{array}$ & $\begin{array}{l}\text { Russian. } \\
\text { CCN D }\end{array}$ \\
\hline 20.016 & & 143 & & 0.272 \\
\hline 0.122 & & - & 0.115 & 0.062 \\
\hline ulphur $\quad 0.104$ & & $05^{8}$ & 0.220 & 0.234 \\
\hline hosphorus o'ro6 & & 030 & 0.034 & - \\
\hline
\end{tabular}

On comparing the analysis of the refined cast-iron of the patent process with those of the English and German processes, it will be seen that while the refined iron of the new process contains no silicon, that of the English and German processes contains 0.63 and 0.62 per cent. respectively; and compared as regards phosphorus, the German process reduces it from 0.56 to 0.50 per cent., or about 0.06 per cent, and the new process reduces it 0.32 per cent., or over five times as much plosphorus is removed by the new process as by the other processes. The slags or silicates are 0.15 per cent. less than in the refined iron of the English finery process. The analysis of the patent refined cast-iron, compared with that of the above English wrought-iron, shows that whilst the wroughtiron contains $0^{\prime} 122$ per cent. of silicon, the refined metal contains none, and compared as regards phosphorus they are about the same.

The analysis of the puddled wrought-iron, made from the refined cast-iron by once heating and rolling the puddled or "muck" bar, shows a purer quality of iron than the most celebrated makers of Europe produced from the purest ores with charcoal.

The economy of using the refined metal in saving cost of labour, fuel, \&c., for the puddling process, has been fully demonstrated by numerous trials. When all the advantages of the process are realised, about one-half of the cost of converting cast-iron into wrought-iron can be saved; and there is an improvement in the quality equal to the difference between ordinary forge pig-iron and charcoal iron.

These advantages are :-
1. Better quality, which is due to the purity of the refined metal; as good qualities of wrought-iron are produced from it as from pig-iron made from the best ores smelted with charcoal.

2. The refined metal being as pure as wrought-iron, with respect to silicon and phosphorus, requires merely decarbonising, with less skill to work it, and greater certainty of the quality of the product.

3. Large saving in cost of production, owing to the shortening of the time of puddling, which is caused by the removal of a large part of the impurities by the re. fining process. White refined iron is decarbonised in twelve to fifteen minutes, and a "heat" or charge of five hundred pounds is puddled in fifty-five minutes, including time of charging, melting the iron, and stirring or puddling or "balling" and removing it from the furnace; grey forge iron requires sixty-five minutes, and foundry iron about seventy minutes. Seven "heats" or charges to a "turn" or a day's labour, are of easier accomplishment than five charges are from the pig-iron from which it was produced; the five charges now require ten hours to convert pig-iron into wrought-iron. It is possible to obtain, with the patent refined metal, by employing three sets of workmen in twenty-four hours, instead of two sets as is now customary, twenty-one charges in twenty-four hours instead of ten charges; and allowing sufficient time for $r \in p a i r s$, the production of any ironwork may be doubled, without additional investment of capital and without additional cost of repairs.

4. Saving of fuel per ton of iron produced, amounting to one-half, caused by increased production.

5. Reduction of general business expenses per ton of iron, amounting to one-half, caused by increased production.

6. Reduction of wages, by reason of the dininished labour, of 40 per cent. per ton of iron.

7. The puddling furnace cinders of the refined metal contain but about one-fourth of the phosphorus, as compared with the cinders resulting from the use of pig-iron; and when smelted produce better qualities of pig-iron.

The cost of refining in the pig-moulds is very little. Fluorspar is a cheapmaterial, and but about seventy pounds are required to refine a ton of iron. The cost is nearly compensated by the saving of the fuel and lime which would be required to reduce the puddle cinders of the refined cast-iron to pig-iron, as they contain but small portions of silica, and will require less fuel and limestone. The residue of the fluorspar and oxide is agglutinated, and remains in the pig moulds, and is pure lime and deoxidised iron ore, and is available as so much lime and ore in the blast furnace.

JAMES HENDERSON

\section{SOME EXPERIMENTS ON COLOUR}

THE theory of colour perception, although in England it has not yet made its way into the text-books, still less into the popular works on science, is fully established with regard to many important points. It is known that our perception of colour is threefold, that is, that any colour may be regarded as made up of definite quantities of three primary colours, the exact nature of which is, however, still uncertain. More strictly stated, the fundamental fact in the doctrine of colour is that, between any four colours whatever given, as well in quantity as in quality, there exists what mathematicians call a linear relation, that is, that either a mixture of two of them (in proper proportions) can be found identical, so far as the eye is able to juclge, with a mixture of the other two; or else that one of them can be matched by a mixture of the other three. There are various optical contrivances by which the mixture spoken of may be effected. In the year I 857, Mr. Maxwell published an account of some experiments with the colour top undertaken to test the theory. From six coloured papers, black, white, red, green, yellow, and blue, dises of two sizes were prepared, which were then slit along a radius so as to admit of being slipped one over the other. Any five out of the six being taken, a match or colour 
equation between them is possible. For instance, if yellow be excluded, the other five must be arranged so that a mixture of red, green, and blue is matched with a mixture of black and white. The large discs of the three colours are taken and slipped on to each other, and similarly the small discs of black and white. When the small discs are placed over the others and the whole made to rotate rapidly on any kind of spinning machine, the colours are blended, those of the large discs and those of the small, each into a uniform tint.

By adjustment of the discs an arrangement may be found after repeated trials, such that the colour of the inner circle is exactly the same both in tint and Iuminosity with that of the outer rim. The quantities of each colour exposed may then be read off on a graduated circle, and the result recorded. For instance (the circle being clivirled into I92 parts), eighty-two parts red mixed with fifty-six green and fifty-four blue, match thirly-seven parts white mixed with 155 black. In this way Maxwell observed the colour equations between each set of five, in all six sets formed by leaving out in turn each of the six colours. Moreover, for greater accuracy each set was observed six times, and the mean taken. But according to the theory these six final equations are not all independent of each other, but if any two of them are supposed known, the others can be found by a simple calculation. Accordingly, the comparison of the calculated and observed equations furnishes a test of the theory: but in practice, in order to ensure greater accuracy, instead of founding the calculations on two of the actually observed equations chosen arbitrarily, it is preferable to combine all the observations into two equations, which may then be made the basis of calculation. In this way, a system of equations is found necessarily consisten with itself, and agreeing as nearly as possible with the actually observed equations. A comparison of the two sets gives evidence as to the truth of the theory according to which the calculations are made, or if this be considered beyond doubt, tests the accuracy of the observations. In Maxwell's experiments the average difference between the calculaied and observed systems amounted to 77 divisions of which the circle carried $\mathrm{rco}$. So gond an arreement is regarded by him as a confirmation of the whole theory; but it seems to me, I confess, that only a very limited part of it is concerned. The axions, in virtue of which it is permitted to combine the colyu equations in the manner required for the calculations, are only such as the following :-If colours which match are mixed with colours which match, the results will match. It is difficult to imagine any theory of colour which will not include them. What proves the threefold character of colour - the most important part of the doctrine-is simply the fact that with any five-coloured papers zuhatever a match can be made, while with less than five it cannot (except in certain particular cases). In regard to this point the value of the quantitative experiments is rather that they show of what sort of accuracy the eye is capable in this kind of observation. Those to whom the subject is new may think at first that if colour be threefold a match ought to be possible between any four colours. And so it is possible if there is no other limitation; but in experiments with the revolving discs, we are subject to a limitation, being obliged to fill up the whole circumference somehow. The difficulty will clear itself up, when it is remembered that one of the five colours may be black, so that with any four colours and black a match can be made with revolving discs.

It was rather for my own satisfaction than with the hope of adding anything new to a subject already so fully and ably treated by Maxwell, that I commenced a repetition of his experiments. The colours used were, roughly speaking, the same as his, as was also the general plan of the observations. The agreement of the calculated and directly observed equations was very good, the average error being only 24 divisions of which the complete circle contained ninety-six, or one-third of the corresponding average error in Mr. Maxwell's Table. A second set of observations and calculations made after a year's interval with a different set of colours gave about the same result. I am inclined to attribute the considerably greater accuracy of my observations rather to an excellent perception of minute differences of colour (to which I have always found my eyes very sensitive) than to greater care in conducting the experiments. One precaution, however, I have found so important as to be worth mentioning. Unless the small discs are very accurately cut and centred, a coloured rim appears on rotation between the two uniform tints to be compared and adjusted to identity, which is exceedingly distracting to the eye, and interferes much with the accuracy of the comparison. One set of observations made with the same care, and apparently as satisfactory as any of the others, puzzled me for some time on account of the great discrepancies with the others which it exhibitel. I have no doubt that the cause lay in the different character of the light on the day in question, which came from the unusually blue sky which sometimes accompanies a high wind. On the other days the light came principally from clouds. I have had no opportunity of confirming this opinion by a repetition of the experiment with a sky of the same degree of blueness, but that the disagreement was not the result of unusually large errors of observation, is, I think, to be inferred from the fact that the observations under the blue sky were as consistent among themselves as any of the other sets. As the point is of some interest, I give the figures in full.

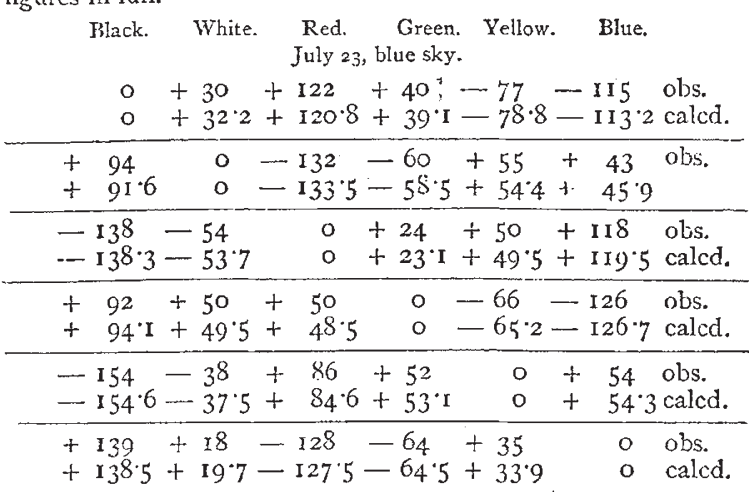

The numbers read off for the big discs are written with the sign + prefixed, and those corresponding to the little discs with Thus the first line may be read : - 30 parts white together with 122 red and 40 green, match 77 yellow and I 5 blue. The upper line of each pair represents the actual observation, and the second is the theoretical equation calculated from two in the manner described. The average difference between the two sets of numbers which may be taken as a measure of the inaccuracy of the observations amounts to I.I. A similar table, formed from the observations of July 20 (cloudy), and which agreed very well with the results of other days, is as follows* :-

\begin{tabular}{|c|c|c|c|c|c|}
\hline $\begin{array}{c}\text { Black. } \\
0 \\
0\end{array}$ & $\begin{array}{r}\text { White } \\
+30 \\
3 \mathrm{I} \cdot \mathrm{r} \\
\end{array}$ & $\begin{array}{r}\quad \text { Red. } \\
+117 \\
116.2 \\
\end{array}$ & $\begin{array}{r}\text { Green. } \\
+\quad 45 \\
44.8 \\
\end{array}$ & $\begin{array}{r}\text { Yellow } \\
-79 \\
79.9 \\
\end{array}$ & $\begin{array}{c}\text { Blue. } \\
- \text { II3 } \\
\text { II } 2.2 \\
\end{array}$ \\
\hline $\begin{array}{r}90 \\
85.9 \\
\end{array}$ & $\stackrel{\circ}{\circ}$ & $\begin{array}{r}-128 \\
128.4\end{array}$ & $\begin{array}{r}-64 \\
635 \\
\end{array}$ & $\begin{array}{r}+56 \\
57^{\circ} \\
\end{array}$ & $\begin{array}{r}+46 \\
\quad 49^{\circ}\end{array}$ \\
\hline $\begin{array}{r}-136 \\
137 \\
\end{array}$ & $\begin{array}{r}-56 \\
55 \\
\end{array}$ & $\begin{array}{l}0 \\
0\end{array}$ & $\begin{array}{r}+22 \\
22 \cdot 3\end{array}$ & $\begin{array}{r}52 \\
50 \\
\end{array}$ & $\begin{aligned}+ & \operatorname{lr} 8 \\
& \end{aligned}$ \\
\hline $\begin{array}{r}+100 \\
99^{\circ} 2\end{array}$ & $\begin{array}{c}+50 \\
51\end{array}$ & $\begin{array}{l}+\quad 42 \\
41^{\circ} 9\end{array}$ & $\begin{array}{l}\circ \\
\circ\end{array}$ & $\begin{array}{r}-64 \\
65\end{array}$ & $\begin{array}{r}-128 \\
127 \cdot 1\end{array}$ \\
\hline $\begin{array}{l}+135 \\
1357\end{array}$ & $\begin{aligned}+ & 2 \mathrm{I} \\
& 21 \cdot 5\end{aligned}$ & $\begin{array}{r}-123 \\
122\end{array}$ & $\begin{array}{l}-69 \\
7 \quad 693\end{array}$ & $\begin{array}{r}+36 \\
34.8\end{array}$ & $\stackrel{\circ}{\circ}$ \\
\hline $\begin{array}{r}-152 \\
152.6\end{array}$ & $\begin{array}{r}-40 \\
\quad 39.5 \\
\end{array}$ & $\begin{array}{r}+80 \\
8 r \\
\end{array}$ & $\begin{array}{r}56 \\
56 \\
\end{array}$ & $\begin{array}{l}0 \\
0\end{array}$ & $\begin{array}{r}56 \\
55\end{array}$ \\
\hline
\end{tabular}

The average error is here $\cdot 95$, showing only a trifling better agreement than the former set, so that the blue sky observations are nearly as self-consistent as those made with cloud-light. Moreover, the agreement is itself very good, being decidedly better than Maxwell's, though his calculations refer to a mean of six sets of observations.

While therefore there is no reason to distrust the results of July 23 any more than of July 20 , the differences between them are much greater than can be ascribed to errors of observation. It will be found that they relate principally to the quantities of red, the numbers under that head being considerably greater for the case of the blue light from the sky. I am not aware whether the difference of sky and cloud light has ever been made the subject of direct investigation, but it would seem a fair inference that it must consist mainly in a relative deficiency of the red rays. If this be so, as I have other grounds for suspecting, the light of the

* These calculations were made by means of Prof. Everett's Proportion table, which seems admirably adapted to work of this sort. 
sky would be similar in composition to that of dilute solutions of copper, which acquire their light blue tint by a partial suppression of the extreme red.* There is no doubt that the colour equations are dependent on the character of the light, as may easily be proved by taking an observation looking all the time through a layer of coloured liquid. It is not, however, the most brilliantly coloured solutions that cause the most disturbance, for anything like a complete stoppage of all the rays which are capable of exciting one of the primary colour sensations would affect both the mixtures to be compared in nearly the same manner, putting the observer in fact very much into the positions of a colour-blind person. Those liquids will be most efficient which have a different action on parts of the spectrum allied in colour. For instance, an aqueous infusion of litmus has a strongly marked action on the yellow ray, stopping it with great energv, even in rather dilute solutions. It is easy to trace the effect of looking through this on most of the colour equations. Consider, for example, the fifth equation of July 20 (that from which the blue is absent) wherein red and grcen are matched against black, white, and yellow. The red and green will for the most part escape absorption, but the white and yellow will be shorn of a part of their yellow rays. The match supposed to have been adjusted without the litmus must evidently be spoiled; the red and green mixture becoming strongly yellow in comparison with the other. In order to restore equivalence the yellow must be considerably increased. On trial I found, I24 black + I9 white +49 yellow matched 121 red +71 green.

It is only the impurity of the colours on the discs that prevents the effect being still more strongly marked, for with the pure colours of the spectrum the most violent alterations are possible. When a match is made between the simple yellow and that compounded of pure red and green, almost any coloured liquid acts unequally on the two parts and destroys the balance. The simple yellow, of course, retains its colour under any absorbing influence, and can only be changed in luminosity. Chloride of copper extinguishes the red component of the compound yellow, which accordingly becomes green. Litmus would leave the compound colour nearly unchanged, while it extinguishes the simple yellow. It is needless to multiply instances.

Before leaving the compound yellow, of whose very existence many are incredulous, I will mention an easy way of obtaining it, which is the more desirable as the use of the pure spectral colours is not very convenient. In order to isolate the red and green rays of the spectrum by means of absorption, the first thing is to find a liquid capable of removing the intermediate yellow and orange. With this object we may fall back on the alkaline solution of litmus, whose opacity to the yellow, and particularly to the orange rays is so marked. The next step is to remove the blue and bluish green, for which nothing is more convenient than the chromate of potash. A mixture of these two liquids in proper proportions, easily found by trial, isolates the green and extreme red rays with considerable perfection, and exhibits in a high degree the phenomenon of $\mathrm{Di}$ chromatism. According to the thickness traversed by the light the red or the green predominates, and there is no difficulty with a given thickness in arranging the strength of the solution so as to give a full compound yellow. It is worth notice in confirmation of the opinion expressed as to the character of the sky-blue, that when a cloud seen through the liquid appears a full yellow, or even orange, the former, if at all intense, acquires a decided green colour. A window backed by well-lighted clouds, when looked at across a room through the liquid and a prism, has a very splendid appearance, the red being isolated on one side, and the green on the other; while the intermediate space, where the two overlap, shows the compound yellow in great perfection. Another liquid, in some respects preferable, which answers the same purpose, may be made by mixing chloride of chromium and bichromate of potash. Through either of them the sodium flame is invisible, though they may easily be made to correspond with it in colour very closely. I tried to obtain a liquid capable of isolating the pure yellow ray, but only with partial success. The

* Direct observations, made since the above was written, show that there is no peculiar deficiency at the red end of the spectrum, but a general falling off as the refrangibility diminishes from one end to the other. If lights from sky and cloud are of equal intensity at the line $C$ in the red the first will be somewhere about twice as bright as the other at $B$ in the green. This is for a well-developed blue light taken from the zenith; but, even with a large allowance, enough difference remains to account for the discrejancies in the two sets of colour disc obsezvations. I have lately found from theory that the power of very small palticles to scatter the rays belonging to different parts of the spectrum varies as the inverse fourth power of the wave length. hest was a mixture of bichromate and permanganate of potash with a salt of copper (sulphate or chloride). The first removes the blue and violet, the second the green, and the third the red, and thus the yellow is isolated in considerable purity. This liquid is very unstable. The comparison of the simple and compound yellow (which nearly matched) was interesting. One was transparent to the sodium flame, the other completely opaque to it. When the two are brought together so that the light has to traverse both, almost complete darkness results, even when the brightest clouds are used. I should mention that it is only when the light is strong that any of these liquids give yellow in full perfection; otherwise the colour is more nearly described as brown, which is, in fact, identical with a dark yellow or orange. The best natural yellows, such as chrome, are partly simple and partly compound, returning all the light which falls upon them except the blue and violet. It is clear that neither a purely simple nor a purely compound yellow can rival them in brilliancy.

Impartial observers, unprejudiced by the results of mixing pigments, or, on the other hand, by experiments on the spectrum, see, so far as I can make out, no connection between the four principal colours-red, yellow, green, and blue. It seems to them quite as absurd that yellow should be compounded of red and green, as it most unquestionably is, as that green should be a compound of blue and yellow, though many have accepted the latter alternative on the authority of painters, and some have even worked themselves into the belief that it is only necessary to Iook at the colours in order to recognise the compound nature of green. My own prejudice would be on the other side, the result of experiments on the compound yellow, which is seen so easily to pass into green on the one side or red on the other. The most impartial opinion that I can form is that there is no real resenzblance between any of the four, and if this be so it is certainly a most remarkable, if not unaccountable, fact. The difficulty is not so much that we are unable to analyse the compound sensation, as to explain why our inability is limited to yellow (and white). For everyone, I imagine, sees in purple a resemblance to its components red and blue, and can trace the primary colours in a mixture of green and blue. Sir John Herschel even thinks that our inability to resolve yellow leaves it doubtful whether our vision is trichromic or tetrachromic, but this seems to me to be going much too far. Surely the fact that the most saturated yellow can be compounded of red and green, deprives it of any right to stand in the same rank with them as primary colours, however little resemblance it may bear to them and blue. Besides, if yellow is to be considered primary, why not also white, which is quite as distinct a sensation as any of the others? Undoubtedly there is much that is still obscure in the mutual relations of the colours-why, for instance, as mentioned by Sir John Herschel, a dark yellow or orange surgests its character so little as to be called by a new name (brown), while a dark blue is blue still. But difficulties such as these should make us all the more determined to build our theories of colour on the solid ground that normal vision is threefold, and that the three primary elements of colour correspond nearly with red, green, and blue. * J. W. Strutt

\section{SCIENTIFIC SERIALS}

THE Quarterly Fournal of Science for January commences a new régime under the sole editorship of $\mathrm{Mr}$. W. Crookes. As will be seen from, the following summary of its contents, all the papers, with only one exception, refer to some department of Physical Science to the exclusion of Natural History. The articles are as follows :-r. "Double Spectra," by W. M. Watts. A részme of the facts known to the present time to modify the conclusions drawn from the earlier spectrum researches of Bunsen and Kirchhoff, from which it was concluded that the spectrum of each element was one and invariable. A plain and a coloured lithographic illustration show the spectrum of copper chloride when volatilised undecomposed, as contrasted with that of the metal; the different spectra of barium, strontium, and calcium obtained at different temperatures; the three spectra of hydrogen, $\mathrm{H} \alpha, \mathrm{H} \beta$, and $\mathrm{H} \gamma$, probably due to differences in temperature; the two spectra of aluminium; the two of nitrogen; and the four spectra which are all probably due to incandescent carbon vapour. 2 "The Great Pyramid of Egypt, from a modern scientific point of view," by C. Piazzi Smyth, Part I. 3. "On the Theory of

* This paper was read before Section A of the Liverpool Meeting of the British Association. 